\title{
Glasgow in Maxillofacial Fractures Patients: Mini Review
}

\author{
Giovanna Franchi Cascarani ${ }^{1}$ \\ ${ }^{1}$ Dentistry student at Paulista \\ University (UNIP). \\ Enrico Affonso Barletta ${ }^{2}$
}

\author{
2 - Medical student at Pontifical \\ ${ }^{2}$ Catholic University of Campinas \\ (PUC-Campinas).
}

\author{
Daniela Prata Tacchelli ${ }^{3}$ \\ ${ }^{3}$ Paulista University (UNIP), \\ Maxillofacial Surgery Department
}

\begin{abstract}
$>$ Background:

Maxillofacial traumas are the most frequent one, and are usually associated with brain injuries that can be measured by the Glasgow Coma Scale (GCS).
\end{abstract}

\section{$>$ Material and Methods:}

We did a mini review of the literature using PubMed as our data base, using "maxillofacial trauma and Glasgow Coma Scale" as key words. Among 73 articles found, we selected 3 articles that together analyzed 213 patients.

\section{$>$ Results:}

It was found that male patients $(77,4 \%)$ were more affected than female $(22,5 \%)$, the average age was 34,6 $\pm 8,32$ years, and the most common mechanism of trauma was vehicle accident. Just 10 patients presented a score between 14 and 15 on the GCS, which showed that most patients had neurological damage in different degrees.

\section{Conclusions:}

It was found that there is a relation between maxillofacial trauma and a decreased level of consciousness. Although, the literature lacks of studies analyzing the relation and presence of an altered mental status and the occurrence of a maxillofacial trauma.

\section{INTRODUCTION}

Maxillofacial trauma and injuries to the cranium are commonly related, especially in high-energy trauma. In those cases, the management of those patients needs to be multidisciplinary because these are challenging cases and requires close cooperation between oral and maxillofacial and neurosurgical teams. ${ }^{1}$
Maxillofacial traumas are usually associated with brain injury, considering that the maxillofacial bones are responsible for protecting the brain, however, some recent investigations have suggested that the face may actually transmit forces directly to the neurocranium, resulting in more serious brain injuries. ${ }^{2,3}$ Because of that it is important to use trauma scoring systems and a multidisciplinary approach for medically and accurately responding to the trauma patient in a timely manner. The closeness of maxillofacial bones to the cranium skull would suggest that there are chances of cranial injuries occurring simultaneously.

In view of this, it is essential that the surgeon be aware of the management of the patients that have maxillofacial fractures associated to brain injury.

The aim of the present study was analyze the relation between maxillofacial trauma and brain injury, using the Glasgow Coma Scale (GCS) as a parameter. We did a mini review of the literature with data of 213 patients using the mechanism of trauma and the GCS to analyze the relation between this two parameters. ${ }^{2}$

\section{MATERIAL AND METHODS}

We did a review of the literature using PubMed as data base, we used "maxillofacial trauma and Glasgow Coma Scale" as key words. Among 73 articles found we selected 3 articles that together analyzed 213 patients. The aim of this study was analyze the relation between maxillofacial trauma and the level of neurological commitment. As our inclusion criteria we used articles that were in English, showed data about maxillofacial traumas and its relation with an altered GCS. Therefore we excluded articles that didn't present the GCS of the patients analyzed, articles presenting data about other fractures/traumas than maxillofacial traumas and also articles written in other languages. 


\section{RESULTS}

\begin{tabular}{|c|c|c|c|c|}
\hline Article - Year - N & Sex & Average Age & Mechanism of trauma & Glasgow \\
\hline Matsumoto et al - $2018-118$ & $\begin{array}{c}\text { Male (85) } \\
\text { Female (33) }\end{array}$ & 44 & $\begin{array}{l}\text { Bicycle accident - } 39 \\
\text { Fall - } 28 \\
\text { Vehicle accident - } 19 \\
\text { Pedestrian - } 16 \\
\text { Others - } 16\end{array}$ & $\begin{array}{c}(4-13)-10 \\
\text { (average) }\end{array}$ \\
\hline Salentijn et al - $2014-47$ & $\begin{array}{l}\text { Male (42) } \\
\text { Female (5) }\end{array}$ & 32 & $\begin{array}{c}\text { Traffic accident - } 26 \\
\text { Violence - } 2 \\
\text { Fall - } 12 \\
\text { Others - } 7\end{array}$ & $\begin{array}{c}(3-8)-27 \\
(9-13)-10 \\
(14-15)-10\end{array}$ \\
\hline Wood et al - $1990-48$ & $\begin{array}{c}\text { Male (38) } \\
\text { Female (10) }\end{array}$ & 28 & $\begin{array}{c}\text { Vehicle accident - } 39 \\
\text { Industrial - } 7 \\
\text { Assault - } 2\end{array}$ & $\begin{array}{l}7-18 \\
12-12 \\
11-18\end{array}$ \\
\hline
\end{tabular}

Table 1:- Present patient's features, the mechanism of trauma and the GCS found in the articles reviewed.

We selected 3 articles that together analyzed 213 patients, $165(77,4 \%)$ male and $48(22,5 \%)$ female, the average age was $34,6 \pm 8,32$ years. Those articles analyzed the mechanism of the maxillofacial trauma and the Glasgow in those patients. Maxillofacial trauma is more frequent in men, the most common mechanism of trauma was: vehicle accident accounting for $39 \%$ (84), followed by fall 18,7\% (40); bicycle accident 18,3\% (39); others $10 \%$ (23); pedestrian 7\% (16); Industrial 3\% (7) and violence $1 \%$ (4). The results of GCS varied between 4 and 15, which means that we couldn't analyze precisely the relation between maxillofacial traumas and neurological damage. However, with this study we could verify that most cases of maxillofacial traumas included neurological damage (less than 15 on the Glasgow Coma Scale). Just 10 patients were between 14 and 15 on the GCS, thus the other $203(95,3 \%)$ patients got a lower score, showing neurological damage in different degrees.

\section{DISCUSSION}

Maxillofacial injuries are associated with a variety of problems including airway compromise, hemorrhage, cervical and neurological injuries. ${ }^{4}$ Medical care must be provided quickly, so that the patient neurological status is assessed as soon as possible. ${ }^{5}$ In our review we saw that young adults were more likely to suffer a maxillofacial trauma (Mean age of 34,6 $\pm 8,32$ years). However, older patients were found to have the highest number of complications, including brain injury, which might be due to impaired capacity to heal and less physiological reserve, compared to younger patients. Patients between 60 and 69 years old showed a worst capacity of recovery when compared to younger patients. $^{2}$ Regarding the patient's sex, male patients showed an important prevalence of maxillofacial traumas in our review, the same found was reported by McGoldrick et al. ${ }^{7}$ Traffic accidents were found as the most common cause of maxillofacial trauma, given that accidents including vehicles, involve a lot of energy. ${ }^{6}$ Same as founded by Al-Hassani et al. ${ }^{8}$ Besides the energy of the trauma; traffic accident usually results in open wounds, causing great blood loss, which increases the brain injury or hemorrhage as a complication. ${ }^{1}$

Other mechanisms of trauma can be founded; such as fall, violence and industrial accidents. All these mechanisms have the potential to cause brain damage to the patients, due to their energy. This energy is the reason why the injury can be so harmful to the patient. ${ }^{4}$ In politrauma patients, it is very unlikely that the facial fractures are the lone-standing cause of the hypovolemic shock, because of the high energy involved in those traumas and the great blood loss. ${ }^{2}$ The main goal of this review was to establish a relation between the maxillofacial traumas and the level of consciousness of the patient measured by the GCS. The literature have very few works presenting this data. However, the few articles we could evaluate showed that maxillofacial trauma patients, usually present a decreased level of consciousness, that was seen by a GCS lower than 15 , therefore $95,3 \%$ of the patients analyzed presented a GCS lower or equal 13. Therefore we saw that there is a relation between those variables and the literature need more articles evaluating this topic.

\section{CONCLUSION}

In sum, usually patient's that suffer a maxillofacial trauma are young adult man. The most common mechanism of trauma are vehicle accidents. There is a relation between the maxillofacial trauma and a decreased level of consciousness. However, the literature lacks of studies analyzing the relation and presence of an altered mental status and the occurrence of a maxillofacial trauma. 


\section{REFERENCES}

[1]. Matsumoto, S., Akashi, T., Hayashida, K., Sekine, K., Orita, T., Funabiki, T., et al. (2018). Transcatheter Arterial Embolization in the Treatment of Maxillofacial Fractures With Life-Threatening Hemorrhage. Annals of plastic surgery, 80(6), 664668.

[2]. Salentijn, E. G., Collin, J. D., Boffano, P., \& Forouzanfar, T. (2014). A ten year analysis of the traumatic maxillofacial and brain injury patient in Amsterdam: complications and treatment. Journal of cranio-maxillo-facial surgery : official publication of the European Association for Cranio-Maxillo-Facial Surgery, 42(8), 1717-1722.

[3]. Wood, M. M., Reilly, P. L., \& David, D. J. (1990). Neuropsychologic outcome after craniofacial fracture. The Journal of craniofacial surgery, 1(4), 163-166.

[4]. Bynoe, R. P., Kerwin, A. J., Parker, H. H., Nottingham, J. M., Bell, R. M., Yost, M. J., ... Wade, M. D. (2003). Maxillofacial Injuries and LifeThreatening Hemorrhage. The Journal of Trauma: Injury, Infection, and Critical Care, 55(1), 74-79. doi:10.1097/01.ta.0000026494.22774.a0

[5]. Harris, T., Rice, S., Watts, B., \& Davies, G. (2010). The emergency control of traumatic maxillofacial haemorrhage. European Journal of Emergency Medicine, 17(4), 230-233. doi:10.1097/mej.0b013e32832b7cd3

[6]. Calderoni DR, Guidi Mde C, Kharmandayan P, Nunes $\mathrm{PH}$. Seven-year institutional experience in the surgical treatment of orbito-zygomatic fractures. J Craniomaxillofac Surg. 2011;39(8):593-599. doi:10.1016/j.jcms.2010.11.018

[7]. McGoldrick DM, Fragoso-Iñiguez M, Lawrence T, McMillan K. Maxillofacial injuries in patients with major trauma. $\mathrm{Br} \mathrm{J}$ Oral Maxillofac Surg. 2018;56(6):496-500. doi:10.1016/j.bjoms.2018.04.001

[8]. Al-Hassani, A., Ahmad, K., El-Menyar, A. et al. Prevalence and patterns of maxillofacial trauma: a retrospective descriptive study. Eur J Trauma Emerg Surg (2019). https://doi.org/10.1007/s00068-01901174-6 